\title{
Rectal burn induced by hot coffee enema ${ }^{1}$
}

A 47-year-old woman underwent a selfadministered coffee enema with hot water for bowel cleansing. She immediately evacuated the enema because of intense rectal pain. She was referred to our clinic 72 hours later with a 3-day history of hematochezia, rectal pain, and pain with defecation. Flexible sigmoidoscopy revealed erythematous, ulcerated mucosa extending to approximately three-fourths the circumference of the rectal mucosa and $18 \mathrm{~cm}$ in length ( $\mathbf{F i g . 1}$ ). There was normal mucosa beyond $18 \mathrm{~cm}$. The patient was sent home with stool softeners. Hematochezia continued for 3 days, after which bowel movements became normal. Pain with defecation continued for 5 days. By the 7th day all symptoms had resolved completely. On the 15th clinical day, endoscopy showed improvement of the rectal mucosa with decreased erythema (๑ Fig. 2). By 6 weeks after initial presentation, the rectal mucosa was normal $(\bullet$ Fig. 3) and the patient had recovered well without any complications such as rectal stricture.

Enemas have long been used for bowel cleansing and for constipation. Coffee enemas are one of many herbal remedies that are being increasingly recommended to patients under the care of holistic practitioners. Some alternative practitioners claim that coffee enemas detoxify the blood or liver as well as provide relief of constipation. The proposed mechanism of action is that caffeine stimulates relaxation of smooth muscles causing dilatation of blood vessels and bile ducts. Enzymes present in coffee stimulate the removal of toxins from the blood and the fluid of the enema results in peristalsis and transit of bile from the duodenum into the rectum [1]. When coffee is used in an enema, care must be taken to ensure that the coffee is cooled prior to use to prevent complications such as rectal burn, permanent rectal stricture resulting from a rectal burn injury [2], and bowel perforation.

Endoscopy_UCTN_Code_CCL_1AD_2AJ

\footnotetext{
${ }^{1}$ The opinions or assertions contained herein are the private views of the authors and are not to be construed as official or as reflecting the views of the US Department of the Army, the US Department of Defense, the Department of the Navy or naval services at large.
}

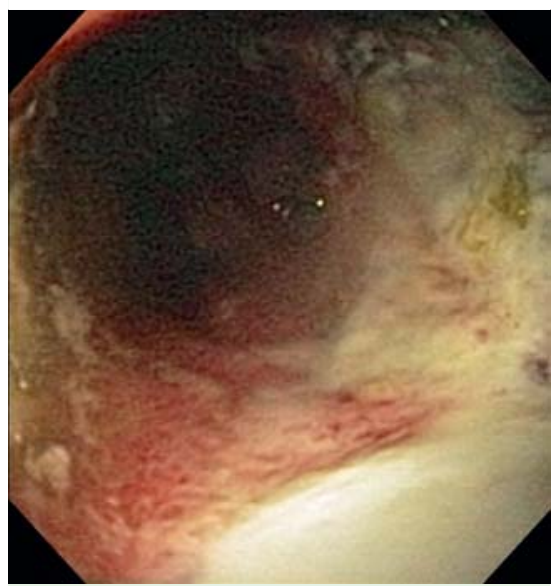

Fig. 1 Erythematous, ulcerated mucosa extending to $18 \mathrm{~cm}$.

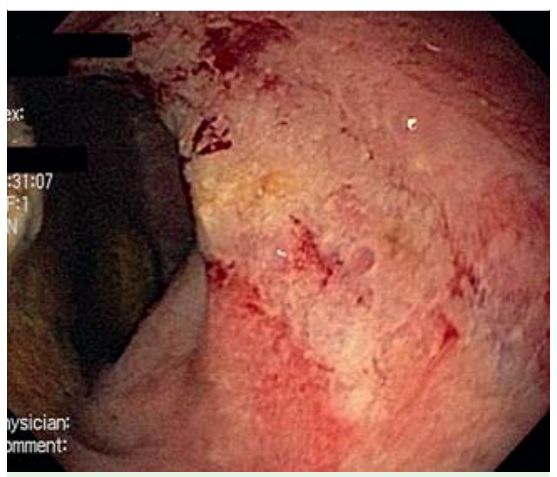

Fig. 2 Decreased erythema of the rectal mucosa 15 days after clinical presentation.

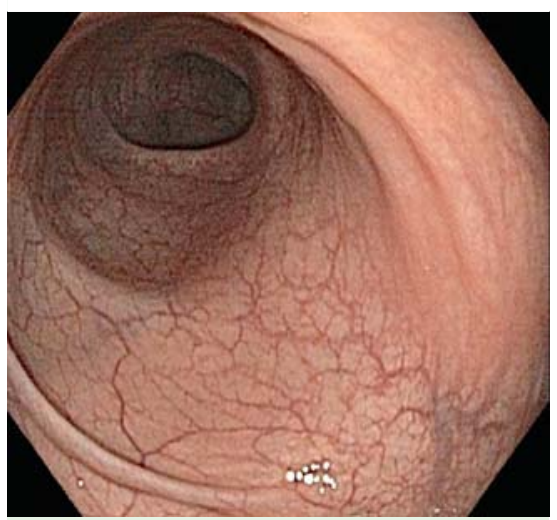

Fig. 3 Normal rectal mucosa 6 weeks after presentation.

\section{E. Jones ${ }^{1}$, W. E. Norris ${ }^{2}$}

Department of Gastroenterology, National Naval Medical Center, Bethesda, Maryland, USA

2 Gastroenterology Service, Walter Reed Army Medical Center, Washington, DC, USA

\section{References}

1 Gerson M. The cure of advanced cancer by diet therapy: a summary of 30 years of clinical experimentation. Physiol Chem Phys 1978; 10: 449-464

2 Sashiyama $\mathrm{H}$ et al. Rectal burn caused by hot-water coffee enema. Gastrointest Endosc 2008; 68: 1008; discussion 1009

\section{Bibliography}

DOI $10.1055 / \mathrm{s}-0029-1215312$

Endoscopy 2010; 42: E26

(c) Georg Thieme Verlag KG Stuttgart · New York . ISSN 0013-726X

\section{Corresponding author}

\section{E. Jones, MD}

Department of Gastroenterology

National Naval Medical Center

8901 Wisconsin Avenue

Bethesda

MD 20889

USA

lindsay.jones2@med.navy.mil 